\title{
Removal of dichloromethane from waste gases in one- and two-liquid- phase stirred tank bioreactors and biotrickling filters
}

\author{
Laura Bailón, Marcell Nikolausz, Matthias Kästner, María C. Veiga, Christian Kennes \\ Water Research, Volume 43, Issue 1, January 2009, Pages 11-20
}

DOI: $10.1016 /$ j.watres.2008.09.031

\begin{abstract}
The removal of dichloromethane (DCM) from polluted air was studied both in biotrickling filters and in continuous stirred tank bioreactors, using either a single-liquid aqueous phase or a combination of an aqueous-organic liquid phase. The presence of the organic phase, i.e. silicone oil, at a volume ratio of $10 \%$ of the liquid phase, increased the maximum EC by about $25 \%$ in the BTF, reaching $200 \mathrm{~g} \mathrm{~m}^{3} / \mathrm{h}$, and by as much as $300 \%$ in the CSTB, reaching $350 \mathrm{~g} \mathrm{~m}^{3} / \mathrm{h}$. Based on data of chloride release in the aqueous phase and carbon dioxide production in the gas phase, complete dechlorination and mineralization of the pollutant could be confirmed. When applying shock loads, a more stable behaviour was observed in the presence of the organic phase. Generally, the completely mixed reactors were also more stable than the plug-flow biotrickling filters, irrespective of the presence of the organic phase. The use of molecular techniques allowed showing that the originally inoculated DCM-degrading Hyphomicrobium strains remained present, although not dominant, after long-term bioreactor operation. Different new bacterial populations did also appear in the systems, some of which were unable to degrade DCM.
\end{abstract}

\section{Keywords}

Activated sludge reactor; Air pollution; Completely mixed reactor; Dichloromethane; Hyphomicrobium; Plug flow; Shock load 


\section{Introduction}

Dichloromethane (DCM) or methylene chloride is a toxic organic compound and a common air pollutant. It is an irritating chemical with fragrant odour, which is harmful to the respiratory system and the central nervous system. Its MAK value (maximal concentration at work) should not exceed $360 \mathrm{mg} / \mathrm{m}^{3}$. The MAK value is the maximum concentration of a single pollutant to which workers may be exposed without health risk for an average continuous exposure of $8 \mathrm{~h} /$ day and $40 \mathrm{~h} /$ week, according to German regulations (DFG, 2008). DCM is produced in large amounts by the chemical industry and is widely used as solvent in paint removers, acetate film production, pharmaceutical industries, metal degreasing and as an aerosol propellant, among others. Different technologies, such as incineration, adsorption and wet scrubbing have been tested for the elimination of DCM from waste gases. However, such methods are costly above all when dealing with relatively low pollutant concentrations and large flow rates. Some factors that significantly affect costs are fuel consumption in case of incineration, catalysts in case of catalytic oxidation processes, activated carbon replacement or regeneration in case of adsorption, and chemicals required for scrubbing. Bioprocesses represent an attractive alternative technology for the removal of DCM from waste gases, based on the activity of cheap biocatalysts operating at room temperature (Kennes and Veiga, 2001).

The biodegradability of DCM was shown for the first time in the early 1980's (Kennes et al., 2006). Different types of bioreactors are available for the removal of VOC as dichloromethane from waste gases. The best choice in terms of reactor configuration depends on factors such as the nature and characteristics of the pollutant as well as the nature of the end products. In case of chlorinated compounds, as DCM, their biodegradation will lead to the formation and release of acid end products. Free liquidphase bioreactors, as biotrickling filters or bioscrubbers, perform usually better than conventional biofilters, in the removal of acid producing pollutants (Kennes and Thalasso, 1998). Some recent studies have also shown that the addition of a second liquid, organic phase, in suspended growth bioreactors may significantly increase the performance of such reactors (Daugulis, 2001). This has mainly been tested with very poorly soluble pollutants, which is the case of some high molecular weight aromatic hydrocarbons and most VOC-compounds. The presence of such an organic phase is particularly interesting when the microbial activity may be inhibited by the presence of high concentrations of a specific pollutant, as it lowers the concentration in the aqueous phase where biodegradation takes place.

In the present study, the removal of dichloromethane was compared in a biotrickling filter (BTF) and a completely mixed stirred tank bioreactor (CSTB), operated under non-aseptic conditions. The reactors were seeded with pure Hyphomicrobium strains and the stability of the inoculated organisms was evaluated after long-term operation. Complete pollutant removal and optimal reactor performance were determined. In a second stage, $10 \%$ (vol:vol) silicone oil was added as organic phase to both reactors and performance was compared to the one-liquid-phase systems. The influence of the organic phase when applying shock loads was studied as well. The fate of the inoculated microorganisms was evaluated after long-term operation. Amplified ribosomal DNA restriction analysis (ARDRA) method ( Massol-Deyá et al., 1997) was used as a fast molecular fingerprinting technique to track the patterns characteristic for the inoculated 
strains. In addition, DCM dehalogenase gene sequences were also targeted as an alternative functional marker.

\section{Materials and methods}

\subsection{Bacteria and medium}

The biotrickling filter (BTF) and the completely stirred tank bioreactor (CSTB) were inoculated with a biomass suspension of Hyphomicrobium KDM2 and KDM4 ( Nikolausz et al., 2006) grown in shake-flasks. Before undertaking the studies reported in this paper, the reactors were operated for about 250 days (eight months) to perform several assays (data not shown). At the end of that period, observations under the microscope showed the presence of a mixed microbial community. As the reactors were operated under non-sterile conditions, after a total of one-year continuous operation samples of both bioreactors were taken in order to characterise the microbial community and to check the presence of the originally inoculated organisms.

The mineral medium used contained per litre distilled water: $1.5 \mathrm{~g} \mathrm{KH}_{2} \mathrm{PO}_{4}, 4.69 \mathrm{~g}$ $\mathrm{Na}_{2} \mathrm{HPO}_{4} \cdot 12 \mathrm{H}_{2} \mathrm{O}, 0.5 \mathrm{~g}\left(\mathrm{NH}_{4}\right)_{2} \mathrm{SO}_{4}, 0.2 \mathrm{~g} \mathrm{MgSO}_{4} \cdot 7 \mathrm{H}_{2} \mathrm{O}, 1 \mathrm{ml}$ of a trace mineral solution and $1 \mathrm{ml}$ of a vitamins solution. The trace mineral solution contained per litre distilled water: $5.3 \mathrm{mg} \mathrm{CaCl}_{2}, 2 \mathrm{mg} \mathrm{FeSO}_{4} \cdot 7 \mathrm{H}_{2} \mathrm{O}, 0.2 \mathrm{mg} \mathrm{MnSO}_{4} \cdot 5 \mathrm{H}_{2} \mathrm{O}, 0.2 \mathrm{mg}$ $\mathrm{CuSO}_{4} \cdot 5 \mathrm{H}_{2} \mathrm{O}, 0.2 \mathrm{mg} \mathrm{ZnSO}_{4} \cdot 7 \mathrm{H}_{2} \mathrm{O}, 0.03 \mathrm{mg} \mathrm{H}_{3} \mathrm{BO}_{3}, 0.4 \mathrm{mg} \mathrm{CoCl}_{2}$ and $4 \mathrm{mg}$ $\mathrm{Na}_{2} \mathrm{MoO}_{4} \cdot 2 \mathrm{H}_{2} \mathrm{O}$. The vitamin solution contained per litre distilled water: $0.2 \mathrm{mg}$ biotin, $0.2 \mathrm{mg}$ folic acid, $0.5 \mathrm{mg}$ riboflavin, $0.5 \mathrm{mg}$ thiamine, $0.5 \mathrm{mg}$ nicotinic acid, $0.001 \mathrm{mg}$ vitamin B12, $0.5 \mathrm{mg}$ p-aminobenzoic acid, $1 \mathrm{mg}$ pyridoxamine and $0.5 \mathrm{mg}$ lipoic acid. The $\mathrm{pH}$ of the medium was adjusted at 7 .

\subsection{Fixed bed biotrickling filter (BTF)}

A scheme of the biotrickling filter is shown in Fig. 1. The glass reactor had an internal diameter of $0.09 \mathrm{~m}$ and a total packed volume of $2.1 \mathrm{~L}$ lava rock. Both the waste gas and the trickling liquid were fed co-currently in a downflow mode. The polluted gas stream was generated by mixing two different air streams. A small stream of air was bubbled through a vaporization chamber containing pure dichloromethane and was mixed afterwards with a large pure air stream in a mixing chamber. Gas-phase concentrations ranging from 0.1 to $15.7 \mathrm{~g} / \mathrm{m}^{3}$ were obtained by changing the flow rate of the dichloromethane stream. The total gas flow rate was kept at $0.084 \mathrm{~m}^{3} / \mathrm{h}$. The gas velocity was $13.20 \mathrm{~m} / \mathrm{h}$ and the empty bed retention time $90 \mathrm{~s}$. 


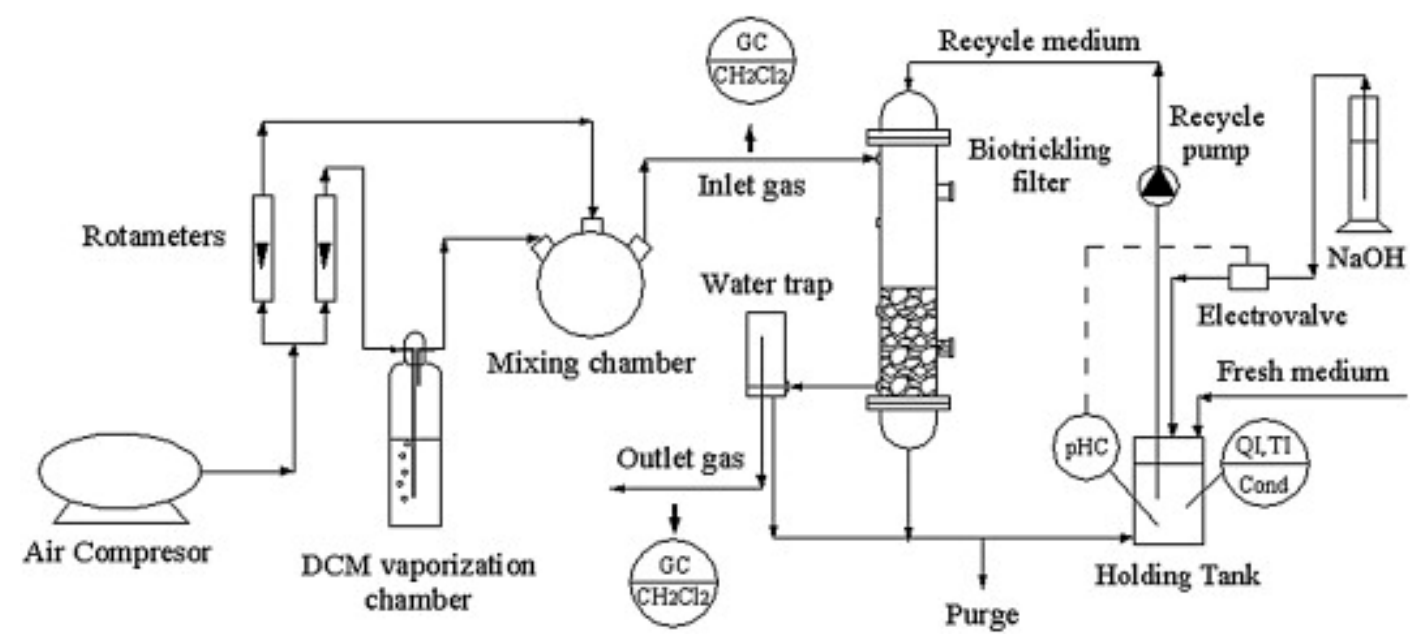

Fig. 1.

Schematic of the biotrickling filter (BTF).

The gas flow rates were adjusted by means of flowmeters (Mohammad et al., 2007). The liquid velocity was kept at $6.9 \mathrm{~m} / \mathrm{h}$ with a Watson Marlow peristaltic pump. The reactor was maintained at room temperature, around $21 \pm 2{ }^{\circ} \mathrm{C}$. The liquid in the holding tank was gently mixed with a magnetic stirrer. The $\mathrm{pH}$ of the recirculated liquid medium was kept between 6.90 and 7.05, by means of a $\mathrm{pH}$ controller coupled to an electrovalve, by dosing a $2 \mathrm{~N} \mathrm{NaOH}$ solution to neutralize the $\mathrm{HCl}$ formed during DCM biodegradation. This resulted in $\mathrm{NaCl}$ accumulation. High concentrations of this salt are known to inhibit the microbial activity (Gälli and Leisinger, 1985, Hartmans and Tramper, 1991, Diks et al., 1994 and Okkerse et al., 1999). Therefore, the conductivity, which is directly related to the $\mathrm{NaCl}$ concentration, was measured in the holding tank and was kept below $28 \mathrm{mS} / \mathrm{cm}^{2}$ by replacing part of the liquid solution when needed. This allowed also to maintain a high enough nutrient supply. The limit of $28 \mathrm{mS} / \mathrm{cm}^{2}$ was obtained from a salt tolerance test showing that up to such a conductivity microbial inhibition was not significant (Bailón et al., 2007). Air samples were regularly taken from the inlet and outlet gas streams.

\subsection{Continuous stirred tank bioreactor (CSTB)}

The experimental set-up is shown in Fig. 2. The $2 \mathrm{~L}$ BioFlo 110 reactor (New Brunswick Scientific) was equipped, among others, with a PCU, a level control module, dissolved $\mathrm{O}_{2}$ and $\mathrm{pH}$ control modules. A water jacket allowed to maintain a constant temperature. 


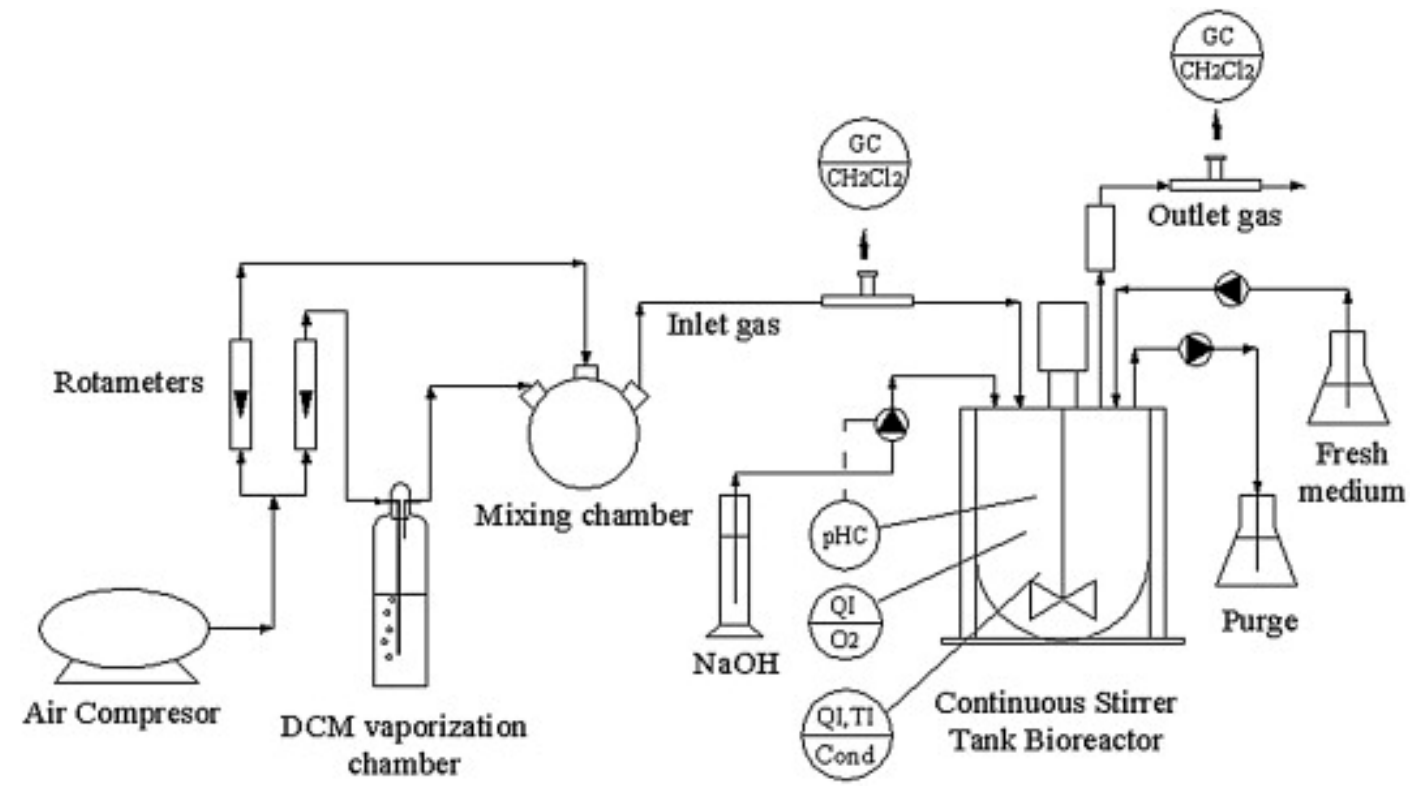

Fig. 2.

Schematic of the completely stirred tank bioreactor (CSTB).

The vessel was filled with $1.5 \mathrm{~L}$ liquid containing the suspended biomass solution. The temperature was kept constant at $30^{\circ} \mathrm{C}$, the turbine stirrer at $400 \mathrm{rpm}$ and the oxygen saturation at $\sim 80 \%$. As in the $\mathrm{BTF}$, the $\mathrm{pH}$ of the culture was kept constant, at 7.0 , by utilizing a $2 \mathrm{~N} \mathrm{NaOH}$ solution as neutralizing agent, automatically added by means of a peristaltic pump. The conductivity was here also kept below $28 \mathrm{mS} / \mathrm{cm}^{2}$. Mineral medium was either added or removed when needed to reach this aim. The total reactor volume was maintained constant. The removed biomass solution was allowed to settle down and the supernatant or the settled biomass recycled to the reactor when needed to maintain a constant biomass concentration. The waste gas stream was created in the same way as for the BTF. The flow rate was also $0.084 \mathrm{~m}^{3} / \mathrm{h}$ while the gas residence time was $64 \mathrm{~s}$. The DCM concentration was determined in the inlet and outlet gas streams of the bioreactor.

\subsection{Partition coefficient}

The air/oil partition coefficient of DCM ( $P_{\mathrm{DCM}}$, oil) was determined at room temperature $\left(\sim 22^{\circ} \mathrm{C}\right)$ and at $30^{\circ} \mathrm{C} .12 \mathrm{ml}$ Teflon coated closed vials were filled with $5 \mathrm{ml}$ each of the silicone oil (viscosity: $10 \mathrm{mPa} \mathrm{s}, 25^{\circ} \mathrm{C}$ ). A known mass of DCM was injected into the vials (by triplicate), vortexed for $1 \mathrm{~min}$ and left at room temperature or at $30{ }^{\circ} \mathrm{C}$ overnight. The concentration of DCM in the oil phase was between 0.22 and $2.29 \mathrm{~kg} / \mathrm{m}^{3}$. After equilibrium was established between the phases, the headspace DCM concentration was measured by GC analysis. The air/oil partition coefficient was then obtained from the slope of the plot of the DCM concentration in the gas phase vs DCM concentration in the liquid phase.

\subsection{Analytical methods}

The DCM concentration of the gas samples was determined with a gas chromatograph, Hewlett Packard HP 6890, equipped with a flame ionisation detector. An HP PLOT-Q column of $30 \mathrm{~m}$ length and $0.53 \mathrm{~mm}$ I.D. was used. The oven temperature was held at 
$180{ }^{\circ} \mathrm{C}$ during $5 \mathrm{~min}$. Carbon dioxide was detected and quantified on an HP 5890 series II gas chromatograph equipped with a TCD (Mohammad et al., 2007). The injection and oven temperatures were 90 and $25^{\circ} \mathrm{C}$, respectively, with the TCD set at $100{ }^{\circ} \mathrm{C}$.

\subsection{Molecular techniques}

DNA was isolated from the bioreactor samples and from the pure and mixed cultures by using DNeasy kit (Qiagen, Hilden, Germany) according to the manufactureŕs protocol. 16S rRNA were amplified from purified DNA by PCR using HotStar Taq polymerase with the buffer supplied by the manufacturer (Qiagen) and universal 16S rRNA gene primers 27f ( Lane, 1991) and 1387r ( Heuer et al., 1997). The annealing temperature was decreased to $50{ }^{\circ} \mathrm{C}$ according to the suggestion of Sipos et al. (2007) in order to reduce PCR bias. PCR amplification of the DCM halogenase gene $(d \mathrm{~cm} A)$ using primers DM for DMrev was performed as described by Vuilleumier et al. (2001). PCR products were separated on a $1.2 \%$ agarose gel stained with ethidium bromide and were visualized with UV excitation.

The 16S rRNA gene PCR amplicons were digested in separate reactions with $1 \mathrm{U}$ of the tetrameric site restriction endonucleases Hin6I and BsuRI (Fermentas, Vilnius, Lithuania) in $1 \times$ buffer supplied by the manufacturer in a final volume of $25 \mu$ l. The digestion mixture was incubated for $3 \mathrm{~h}$ at $37^{\circ} \mathrm{C}$ to ensure full digestion of the PCR products. The fragments were separated by electrophoresis for $35 \mathrm{~min}$ at $100 \mathrm{~V}$ in a $1.6 \%$ agarose gel in $1 \times$ TAE buffer.

Partial 16S rRNA gene sequence of two strains was determined using the Big Dye Terminator Cycle Sequencing Kit V3.1 (Applied Biosystems, Foster City, CA, USA), according to the manufacturer's protocol. Primers used for 16S rDNA sequencing reactions were 27F and 907R (Lane, 1991). Sequencing reaction mixtures were separated with an ABI PRISM 3100 DNA Analyzer (Applied Biosystems). Analysis of sequences and homology searches were completed using the BLAST algorithm with BLAST server of the National Centre for Biotechnology Information (Altschul et al., 1997). The partial sequences determined in this study have been deposited in the NCBI database under accession numbers FM177766 and FM177767.

\section{Results and discussion}

\subsection{Partition coefficients}

The DCM air/water and air/oil partition coefficients appearing in Table 1 show that DCM is 10 times more soluble in silicone oil than in water.

Table 1.

DCM partition coefficients air/oil, air/water.

\begin{tabular}{|l|l|l|}
\hline Temperature $\left({ }^{\circ} \mathrm{C}\right)$ & 22 & 30 \\
\hline$P_{\mathrm{DCM}}$, water $\left[(\mathrm{mg} / \mathrm{L})_{\mathrm{air}} /(\mathrm{mg} / \mathrm{L})_{\text {water }}\right]($ Diks, 1992$)$ & 0.07 & 0.11 \\
\hline \hline$P_{\mathrm{DCM}, \text { oil }}\left[(\mathrm{mg} / \mathrm{L})_{\mathrm{air}} /(\mathrm{mg} / \mathrm{L})_{\text {oil }}\right]($ this study) & $6 \times 10^{-3}$ & $7.7 \times 10^{-3}$ \\
\hline
\end{tabular}




\subsection{Performance of one-liquid-phase bioreactors}

Dichloromethane is relatively water soluble despite being a typical volatile air pollutant. It is sometimes also found in wastewaters (Moura et al., 2007) and its solubility in aqueous phase is around $19.4 \mathrm{~g} / \mathrm{L}$ at room temperature (Kennes et al., 2006). Although its Henry coefficient is somewhat higher than $10^{-2}$, DCM removal should certainly be feasible in either biotrickling filters or bioscrubbers, i.e. stirred tank bioreactors. Conversely, conventional biofilters would not be the best choice, as confirmed by the poor performance reported for such reactors for DCM removal ( Ergas et al., 1994). Although DCM is a common industrial air pollutant, only few research papers have been published on its removal from waste gases in bioreactors. The main objective of this experiment was to compare the removal of DCM in a biotrickling filter and in a stirred tank bioreactor. Although biotrickling filters have most often been used so far, industries already having a biological wastewater treatment plant as, for example, an activated sludge bioreactor, could advantageously feed the waste gas to such bioreactor with limited additional cost. In order to compare the efficiency of a biotrickling filter and a stirred tank bioreactor, both systems were started up simultaneously, and the inlet DCM concentration was gradually increased. Fig. 3 shows elimination capacity data vs inlet load for the BTF, while Fig. 4 shows the same data for the CSTB, as well as the corresponding removal efficiencies. Comparison of both figures allows to make some interesting observations. With respect to the maximum elimination capacity obtained in each case, a 45\% higher value was reached in the BTF compared to the CSTB, namely $110 \mathrm{~g} / \mathrm{m}^{3} \mathrm{~h}$ in case of the suspended growth bioreactor vs $160 \mathrm{~g} / \mathrm{m}^{3} \mathrm{~h}$ in the attached growth system. Considering that the BTF was operated at room temperature, while the CSTB was operated at $30^{\circ} \mathrm{C}$, the higher performance of the BTF would most probably even have been somewhat more significant if both systems had been operated at the same temperature. When focusing on the removal efficiencies, more than $90 \%$ removal was always maintained in the CSTB even when reaching the maximal elimination capacity of $110 \mathrm{~g} / \mathrm{m}^{3} \mathrm{~h}$. Conversely, in the packed bed bioreactor, removal efficiencies exceeding $80 \%$ could only be maintained at loads below $40 \mathrm{~g} / \mathrm{m}^{3} \mathrm{~h}$. The performance curve gradually deviated from the $100 \%$ removal line when further increasing the load. The removal efficiency did hardly reach $50 \%$ at the maximum elimination capacity of $160 \mathrm{~g} / \mathrm{m}^{3} \mathrm{~h}$ in the BTF, corresponding to a load of almost $350 \mathrm{~g} / \mathrm{m}^{3} \mathrm{~h}$. This does also confirm data previously published on DCM removal in BTF ( Hartmans and Tramper, 1991 and Okkerse et al., 1999). For example, the maximum elimination capacity reached by Hartmans and Tramper (1991) in a BTF was $103.5 \mathrm{~g} / \mathrm{m}^{3} \mathrm{~h}$ with a removal efficiency of only $59.3 \%$. In that study, RE above $80 \%$ were only possible at loads below $20-30 \mathrm{~g} / \mathrm{m}^{3} \mathrm{~h}$. The present data suggest that, although the one-liquid-phase CSTB does not allow reaching maximum elimination capacities as high as the one-liquidphase BTF, it allows maintaining much higher removal efficiencies at high loads. 

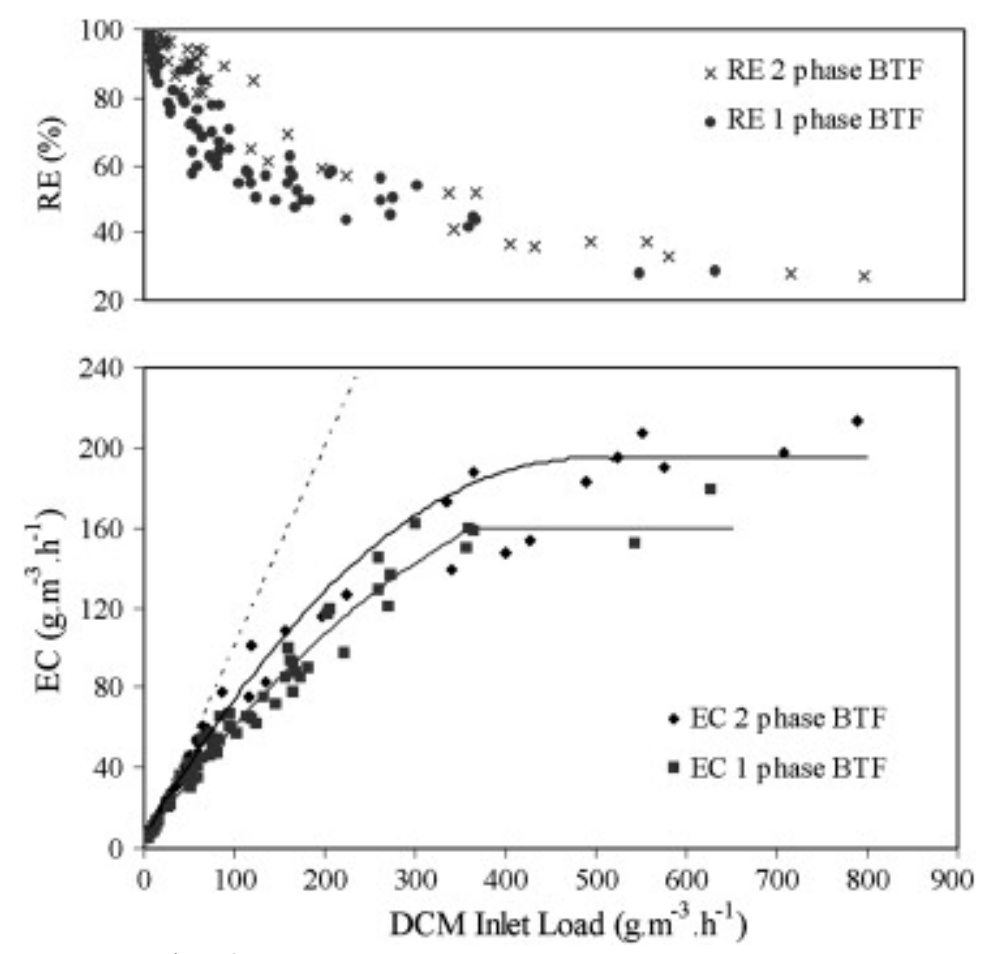

Fig. 3.

EC and RE vs DCM-inlet load in one- and two-liquid-phase biotrickling filters.
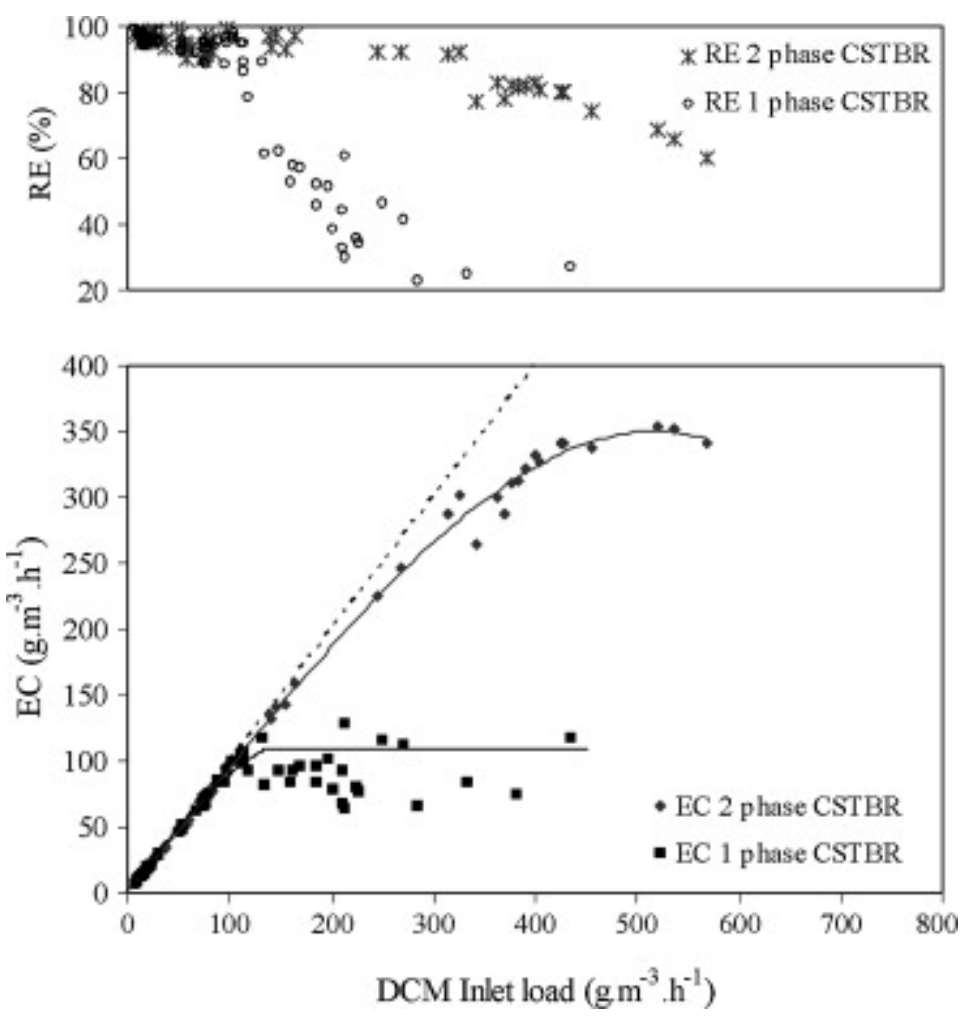

Fig. 4.

EC and RE vs DCM-inlet load in one- and two-liquid-phase Completely Stirred Tank Bioreactors. 


\subsection{DCM mineralization and mass balance calculations}

Carbon dioxide and hydrogen chloride are both end products of DCM biodegradation, according to the following stoichiometric equation, when neglecting biomass growth (Kennes et al., 2006):

$\mathrm{CH}_{2}-\mathrm{Cl}_{2}+\mathrm{O}_{2} \rightarrow \mathrm{CO}_{2}+2 \mathrm{HCl}$

In order to confirm, respectively, complete dechlorination and complete mineralization, both the amounts of $\mathrm{HCl}$ and $\mathrm{CO}_{2}$ formed were checked.

If complete dechlorination takes place, $2 \mathrm{~mol} \mathrm{NaOH}$ would be needed to neutralize the acid formed from the biodegradation of 1 mol DCM, according to Eqs. (1) and (2).

$2 \mathrm{HCl}+2 \mathrm{NaOH} \rightarrow 2 \mathrm{NaCl}+2 \mathrm{H}_{2} \mathrm{O}$

Since the amount of DCM fed to the reactors is known, by recording the amount of sodium hydroxide consumed and used to neutralize the $\mathrm{HCl}$ formed, it was possible to confirm that complete dechlorination took place in both reactors, since that experimental value matched with the calculated value based on Eqs. (1) and (2).

Regarding $\mathrm{CO}_{2}$ data, generally higher carbon dioxide concentrations were generated in the reactors than the ones expected from the DCM load and stoichiometric equation. This has sometimes already been observed and reported by others and can be attributed to phenomena as endogenous respiration. Based on the above results, complete dechlorination was clearly proven and complete mineralization could reasonably be assumed.

\subsection{Stability of inoculated strains}

The presence of the inoculated strains after one-year reactor operation was investigated by amplified ribosomal DNA restriction analysis (ARDRA) and by the detection of the DCM dehalogenase gene. Fig. 5 shows the comparison of the restriction pattern obtained from the inoculated strains and from both reactors. Re-isolation attempts of the DCM-degrading Hyphomicrobium strains from the BTF resulted in two mixed cultures designated as DCM A and DCM B. While the ARDRA pattern specific for the Hyphomicrobium strains is clearly highly present in the CSTR, careful inspection of the Hin6I pattern ( Fig. 5B) of the BTF suggests that Hyphomicrobium KDM strains were not the predominant microorganisms in the sample. Mineral medium plates under DCM atmosphere ( Nikolausz et al., 2005) were used for re-isolation of the potential degraders in the system. The first isolation attempt resulted in mixed cultures based on direct sequencing of the PCR products. The major bands of the ARDRA patterns of these two mixed cultures corresponded to the patterns of the BTF. Further purification steps resulted in pure cultures designated as DCM F1 and DCM F2. The ARDRA patterns of the DCM F1 corresponded to the major band of the BTF samples (data not shown). However, these strains grew very slowly on the mineral medium plate without any detectable DCM degradation. While the activity of the original Hyphomicrobium strains resulted in a strong colour change of the $\mathrm{pH}$ indicator added to the plate, such colour change was not observed with the DCM F1 and F2. After the second transfer on mineral medium plate the strains did not grow at all. DCM F1 was identified as 
Stenotrophomonas maltophilia (100\% identity, 840/840 bp) and DCM F2 was closely related to a Mesorhizobium sp. (98\%, 636/643 bp).

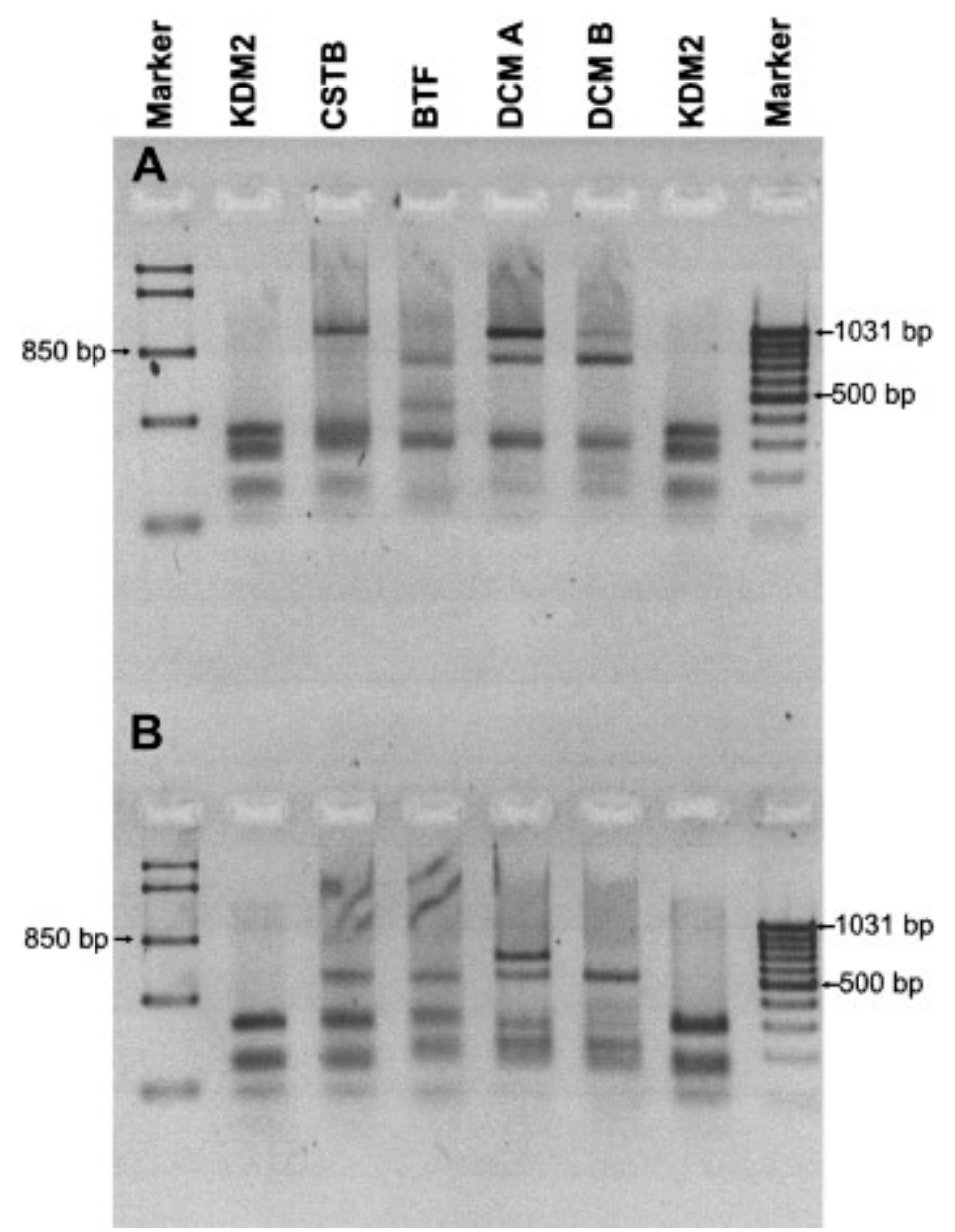

Fig. 5.

ARDRA patterns of the microbial communities and cultures retrieved from the different reactors by using Hin6I (A) and BsuRI (B) restriction enzymes. Samples were run parallel with molecular weight markers (Marker).

Figure options

The DCM dehalogenase gene was not detected in these pure cultures (Fig. 6) but it was detected in the parent mixed culture. The functional gene was also present in the two reactor samples (Fig 6) which indicates that the functionality is linked to the presence of the DCM dehalogenase gene. Our data suggest that the horizontal transfer of the functional gene has not occurred. 


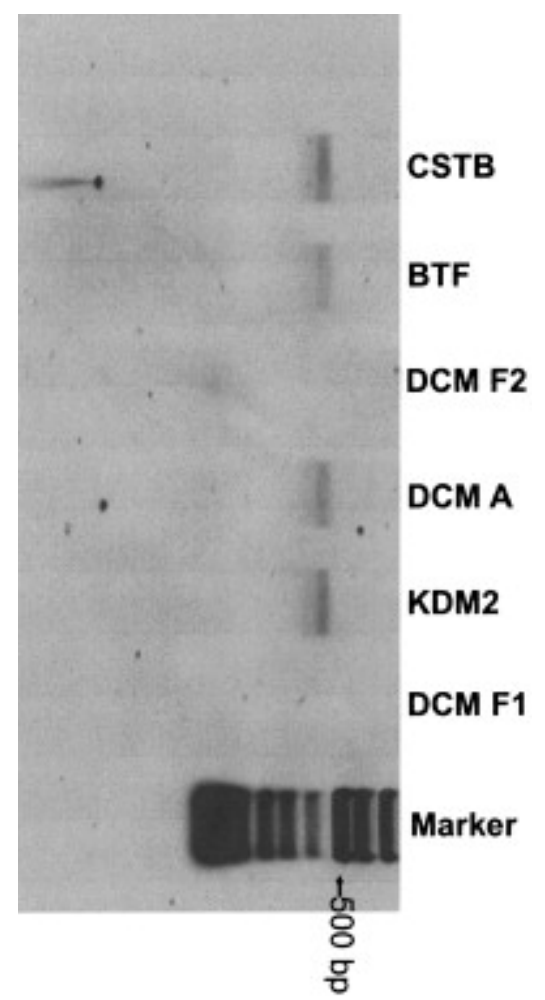

Fig. 6.

PCR amplification and confirmation of the presence of the DCM dehalogenase by agarose gel electrophoresis. Samples were run parallel with a molecular weight marker (Marker).

Although not so many data are available in the literature, some researchers observed that in gas-phase bioreactors inoculated microorganisms may remain dominant after several months operation, above all under rather selective or extreme conditions, as observed in some fungal biofilters (Estévez et al., 2005 and Jin et al., 2007). Conversely, other researchers observed that sometimes bacteria originally inoculated in such bioreactors may still remain present but not necessarily as dominant population. Sercu et al. (2005) used Hyphomicrobium VS strain as inoculum in a two-stage biotrickling filter for the removal of hydrogen sulphide and dimethyl sulphide. After a few weeks operation, the strain was not anymore the dominant microorganism in the reactor. A similar result was observed by Moller et al. (1996) where the introduced Pseudomonas putida strain represented only a minor part of the community, i.e. around $4 \%$, but corresponded to about $65 \%$ of the toluene degraders in a BTF. These results are in good agreement with our findings that the inoculated microorganisms can become a minor part of the community after short-term operation but may still be responsible for a considerable part of the biodegradation. Although PCR bias caused by preferential amplification may skew the relative abundance of different populations obtained by molecular techniques, several recent studies showed that non-stringent PCR conditions as used in this study can reduce this effect ( Ishii and Fukui, 2001 and Sipos et al., 2007). 


\subsection{Performance of two-liquid-phase bioreactors}

In waste gas treatment, the use of a second, organic, liquid phase is known to be able to significantly increase the bioreactors efficiency mainly in case of hardly water soluble pollutants and for toxic compounds, which will be released slowly from the organic to the aqueous phase as biodegradation proceeds. Although DCM is not very poorly soluble in water, the effect of adding an organic phase was checked.

As with the one-liquid-phase systems, the inlet DCM concentration was gradually increased in order to evaluate both reactors' performance. Data of EC vs load as well as the corresponding removal efficiencies are shown in Fig. 3 and Fig. 4, respectively, for the BTF and the CSTB and are compared with the results of the one-liquid-phase reactors. It can be seen that the presence of a second, organic, phase improved the overall performance. However, such improvement was much less significant in the BTF than in the CSTB. Indeed, when adding $10 \%$ silicone oil to the BTF, the maximum EC increased by $25 \%$, reaching $200 \mathrm{~g} / \mathrm{m}^{3} \mathrm{~h}$ to be compared to $160 \mathrm{~g} / \mathrm{m}^{3} \mathrm{~h}$ for the one-liquidphase BTF. High RE, exceeding $80 \%$, could only be maintained up to a load of about $80 \mathrm{~g} / \mathrm{m}^{3} \mathrm{~h}$, after which the performance curve started deviating from the $100 \%$ removal line ( Fig. 3). Conversely, in the two-liquid-phase CSTB, more than $80 \%$ RE could be maintained up to a load of about $330 \mathrm{~g} / \mathrm{m}^{3} \mathrm{~h}$, corresponding to an inlet DCM concentration of about $6 \mathrm{~g} / \mathrm{m}^{3}$. The maximum EC in this system was $350 \mathrm{~g} / \mathrm{m}^{3} \mathrm{~h}$, which is more than three times higher than in the one-liquid-phase CSTB. To the best of our knowledge, this is also almost three times higher than the best results reported so far for DCM removal in the literature ( Table 2). Information on two-liquid-phase BTF is very scarce in the literature. Although a few researchers have studied the removal of VOC from polluted air in two-liquid-phase stirred tank bioreactors ( Boudreau and Daugulis, 2006, Césario et al., 1995, Déziel et al., 1999 and Davidson and Daugulis, 2003), there are only very few reports systematically comparing the removal of such pollutants in one- and two-liquid-phase systems. One study reported on the removal of hexane in a two-liquid-phase BTF, in which EC close to $100 \mathrm{~g} / \mathrm{m}^{3} \mathrm{~h}$ was reached with $90 \% \mathrm{RE}$ ( Van Groenestijn and Lake, 1999). Although the data were not compared to any control system with one single-liquid-phase in that study, such EC is slightly higher than those commonly reported in the literature for one-liquid-phase BTF ( Kennes and Veiga, 2001). A much more recent study compared the removal of that same pollutant, namely hexane, in fungal BTF and CSTB, with either one- or two-liquid-phases ( Arriaga et al., 2006). The authors observed an increase in the maximum EC from 110 to $180 \mathrm{~g} / \mathrm{m}^{3} \mathrm{~h}$ in their BTF and from 50 to $120 \mathrm{~g} / \mathrm{m}^{3} \mathrm{~h}$ in the stirred tank reactor, respectively, with oneor two-liquid-phases. This means a $60 \%$ improvement in case of the BTF and a 2.4 times increase of the maximum EC in the suspended growth bioreactor, confirming that the improvement is significantly more important in CSTB than in BTF, when adding an organic phase. The better results obtained with the two-liquid-phase CSTB compared to the two-liquid-phase BTF could be explained by the formation of many small oil droplets in suspension in the aqueous phase as a result of the high agitation speed used in the CSTB which is highly favourable for an optimal and fast mass transfer of the pollutant from the organic phase to the aqueous phase where biodegradation takes place. Such behaviour is not found in packed bed bioreactors. 
Table 2.

DCM removal from waste gases in bioreactors.

\begin{tabular}{|l||l|l|l||}
\hline Reactor type & $\begin{array}{l}\text { Elimination } \\
\text { (apacity }\left(\mathbf{g} / \mathbf{m}^{\mathbf{3}} \mathbf{h}\right)\end{array}$ & $\begin{array}{l}\text { Corresponding RE } \\
\mathbf{( \% )}\end{array}$ & References \\
\hline $\begin{array}{l}\text { BTF (one- } \\
\text { liquid-phase) }\end{array}$ & 157 & - & $\begin{array}{l}\text { Diks and Ottengraf, } \\
1991\end{array}$ \\
\hline $\begin{array}{l}\text { BTF (one- } \\
\text { liquid-phase) }\end{array}$ & 103.5 & 59.3 & $\begin{array}{l}\text { Hartmans and } \\
\text { Tramper, 1991 }\end{array}$ \\
\hline $\begin{array}{l}\text { BTF (one- } \\
\text { liquid-phase) }\end{array}$ & 102 & 70 & $\begin{array}{l}\text { Okkerse et al., } \\
1999\end{array}$ \\
\hline $\begin{array}{l}\text { Compost } \\
\text { biofilter }\end{array}$ & 10.3 & 98 & Ergas et al., 1994 \\
\hline $\begin{array}{l}\text { BTF (one- } \\
\text { liquid-phase) }\end{array}$ & 160 & 44 & This study \\
\hline $\begin{array}{l}\text { BTF (two- } \\
\text { liquid-phase) }\end{array}$ & 195 & 62 & This study \\
\hline $\begin{array}{l}\text { CSTB (one- } \\
\text { liquid-phase) }\end{array}$ & 117 & 68 & This study \\
\hline $\begin{array}{l}\text { CSTB (two- } \\
\text { liquid-phase) }\end{array}$ & 351 & 92 & \\
\hline
\end{tabular}

\subsection{Shock loads}

In case of shock loads, the presence of an organic phase is expected to buffer the inhibitory effect of the sudden higher pollutant concentrations in the feed. However, only few experimental data are available in the literature to evaluate this potentially favourable effect of using mixed aqueous-organic phases in CSTB operated under transient or high load conditions (Nielsen et al., 2005, Boudreau and Daugulis, 2006 and Aldric and Thonart, 2008) and no data are available for BTF. Some results have also been published on the effect of placing an oil-absorber prior to a one-liquidphase suspended growth bioreactor when applying shock loads of either monochlorobenzene (Oliveira and Livingston, 2003) or dichloroethane (DCE) (Koutinas et al., 2006). Such configuration showed that a previous oil absorption stage allows to buffer shock loads and avoid biomass inhibition and/or wash-out. In the present research both liquid phases, aqueous and organic, were combined in one single stage, namely the bioreactor. Three different experiments were performed with the four systems, i.e. one- and two-liquid-phase BTF and CSTB: (1) switching from a "low" load $\left(15 \mathrm{~g} / \mathrm{m}^{3} \mathrm{~h}\right)$ to a "low" overload $\left(200 \mathrm{~g} / \mathrm{m}^{3} \mathrm{~h}\right)$, (2) switching from a "medium" load $\left(50 \mathrm{~g} / \mathrm{m}^{3} \mathrm{~h}\right)$ to a "medium" overload (250-300 g/m $\left.\mathrm{m}^{3} \mathrm{~h}\right)$, and (3) switching from a "high" load $\left(70 \mathrm{~g} / \mathrm{m}^{3} \mathrm{~h}\right)$ to a "high" overload $\left(500 \mathrm{~g} / \mathrm{m}^{3} \mathrm{~h}\right)$. The results showing the loads, EC and corresponding RE during the overloads are shown in Fig. 7, Fig. 8 and Fig. 9 for experiments (1), (2), and (3), respectively. The data of Fig. 7 show that the low overload inhibits all the systems except the two-liquid-phase CSTB, in which the RE remained close to $100 \%$ throughout the entire duration of the shock load. Actually, this is not surprising as a shock load of $200 \mathrm{~g} / \mathrm{m}^{3} \mathrm{~h}$ is still below the maximum EC reachable in 
that system ( Fig. 4). Regarding the other three systems, although the one-liquid-phase CSTB was previously shown to exhibit the lowest maximum EC under normal conditions (110 g/m $\mathrm{m}^{3}$ h) ( Fig. 4) compared to both BTF (160 and $200 \mathrm{~g} / \mathrm{m}^{3}$ h) ( Fig. 3), that suspended growth bioreactor was less inhibited during the shock load than the BTF, as can easily be seen from the RE data ( Fig. 7). In the one-liquid-phase CSTB, the RE dropped later and less than in the packed bed bioreactors. This can easily be explained by the flow regime in each one of these systems. Indeed, the CSTB is basically a completely mixed reactor, while plug-flow regime is typically found in packed bed BTF ( Mendoza et al., 2004). In the mixed tank, the high inlet concentration reaching the reactor is immediately diluted in the whole reactor volume. Thus, the biocatalyst is actually not exposed to very high pollutant concentrations during the shock load, resulting in minimal inhibition. Therefore, the RE does only start dropping around the end of the 6-h shock load. In case of both BTF, the RE dropped almost immediately once applying the shock load because the attached biomass in both plug-flow bioreactors is directly exposed to the high, inhibitory, inlet concentration. A quite similar behaviour is observed in Fig. 8, when increasing the shock load to a somewhat higher value: almost no inhibition in the two-liquid-phase CSTB, slow and little inhibition in the one-liquid-phase CSTB, and immediate and more significant inhibition in both BTF. In the third experiment, the shock load $\left(500 \mathrm{~g} / \mathrm{m}^{3} \mathrm{~h}\right)$ was well above the critical load of all four bioreactors. In such case, inhibition appears in all four systems. Nevertheless, the two-liquid-phase CSTB is the least affected, followed by the oneliquid-phase CSTB, where the RE dropped to minimum values of $60 \%$ and $50 \%$, respectively, at the end of the 6-h shock load. In the BTF, inhibition seemed to be slightly less in the two-liquid-phase bioreactor although the difference was not really significant compared to the one-liquid-phase configuration ( Fig. 9). Both BTFs quickly reached a minimum value close to $40 \%$ which remained almost constant throughout the overload period. This does again show the positive effect of the oil phase in the CSTB, combined to a better behaviour of completely mixed systems compared to packed bed bioreactors. 

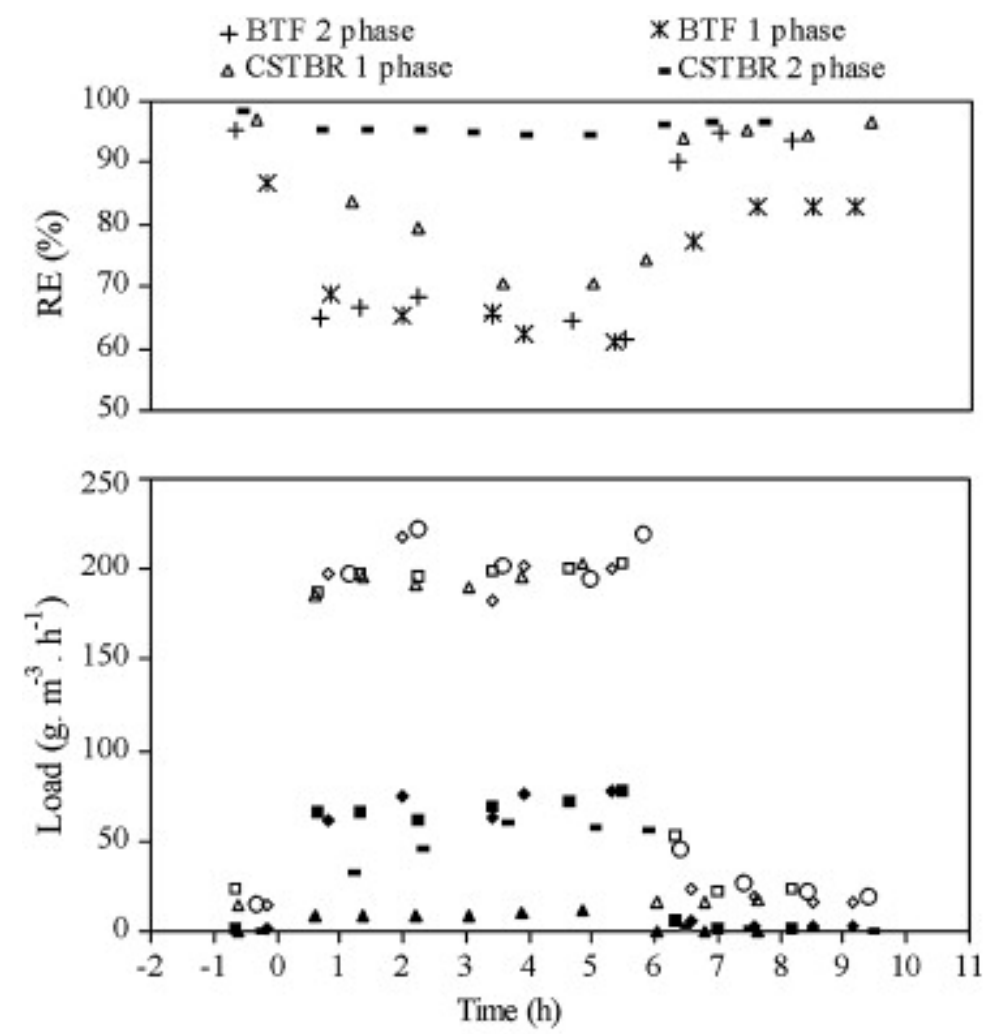
- BTF Inlet Load 1 phase
- BTF Outlet Load 1 phase
a BTF Inlet load 2 phase
- BTF Outlet load 2 phase
o CSTBR Inlet Load 1 phase
$\triangle$ CSTBR Inlet Load 2 phase
- CSTBR Outlet Load 1 phase
- CSTBR Outlet Load 2 phase

Fig. 7.

Inlet load, outlet load (i.e., EC) and RE vs time during shock load experiment \#1. 

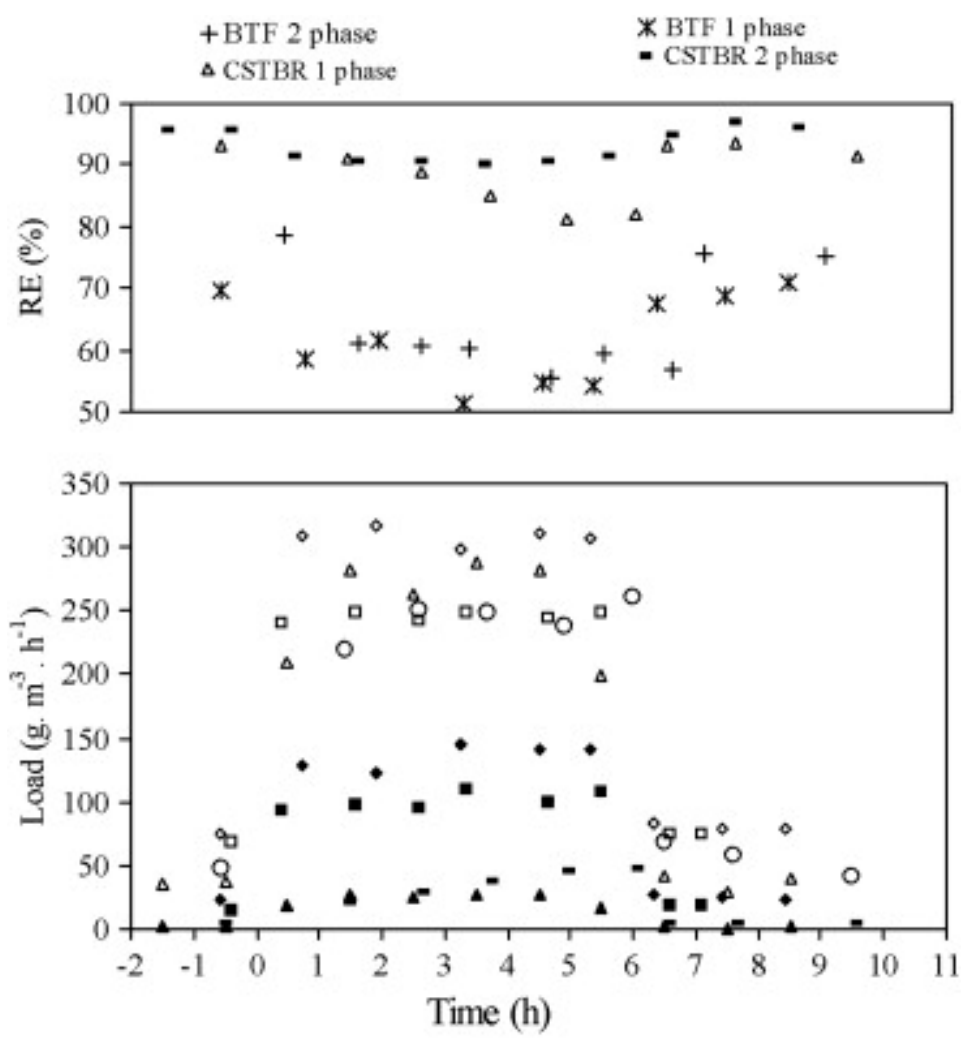

$\begin{array}{ll}\text { - BTF Inlet Load } 1 \text { phase } & \text { - BTF Outlet Load } 1 \text { phase } \\ \text { a BTF Inlet load } 2 \text { phase } & \text { - BTF Outlet load } 2 \text { phase } \\ \text { - CSTBR Inlet Load } 1 \text { phase } & \Delta \text { CSTBR Inlet Load } 2 \text { phase } \\ \text { - CSTBR Outlet Load } 1 \text { phase } & \text { - CSTBR Outlet Load } 2 \text { phase }\end{array}$

Fig. 8.

Inlet load, outlet load (i.e., EC) and RE vs time during shock load experiment \#2. 

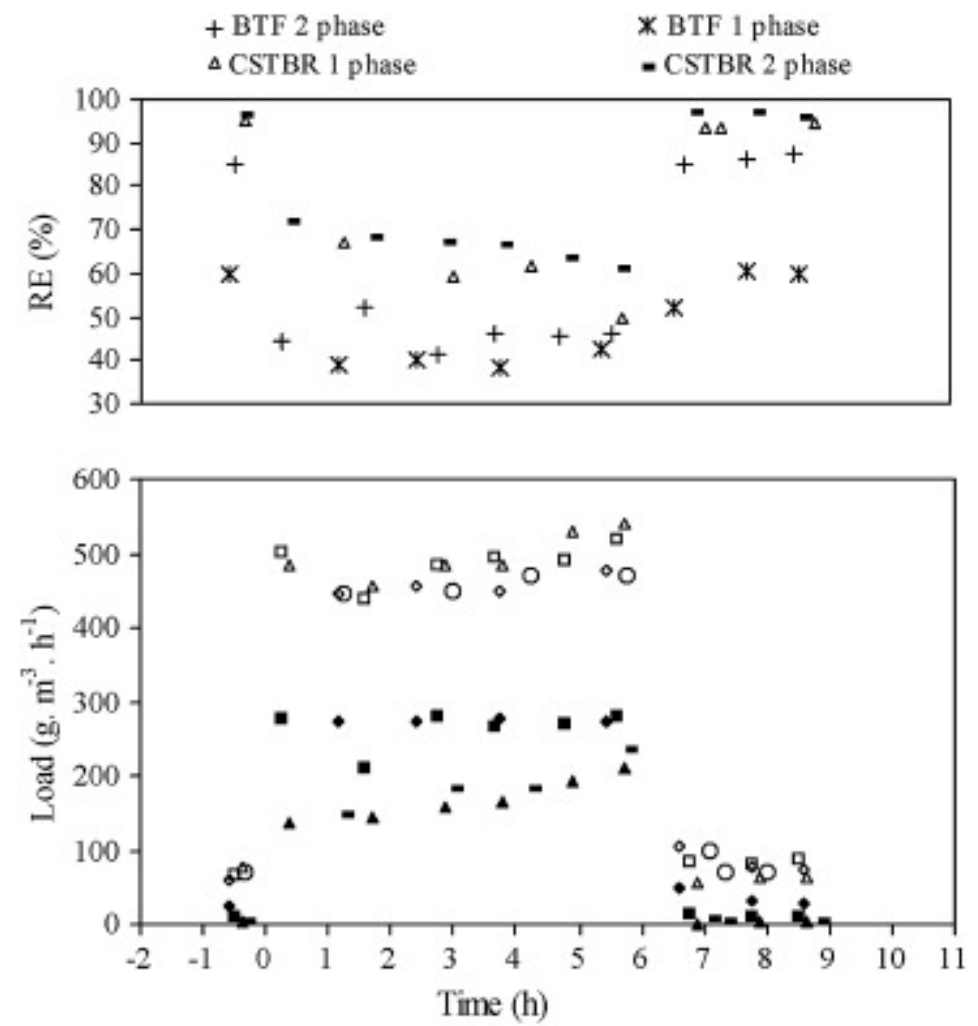

$\begin{array}{ll}\text { - BTF Inlet Load } 1 \text { phase } & \text { - BTF Outlet Load } 1 \text { phase } \\ \text { a BTF Inlet load } 2 \text { phase } & \text { - BTF Outlet load } 2 \text { phase } \\ \text { o CSTBR Inlet Load } 1 \text { phase } & \triangle \text { CSTBR Inlet Load } 2 \text { phase } \\ \text { - CSTBR Outlet Load } 1 \text { phase } & \Delta \text { CSTBR Outlet Load } 2 \text { phase }\end{array}$

Fig. 9.

Inlet load, outlet load (i.e., EC) and RE vs time during shock load experiment \#3.

\section{Conclusions}

The two-liquid-phase CSTB performs always better than the other three bioreactors, both in terms of maximal performance (highest maximum EC and highest RE) and in terms of its resistance against shock loads.

The BTF (either with one- or two-liquid-phases) reaches higher maximum EC than the one-liquid-phase CSTB. Nevertheless, up to its critical load the CSTB performs better as its RE remains close to $100 \%$ up to that critical load, i.e. about $110 \mathrm{~g} / \mathrm{m}^{3} \mathrm{~h}$. The RE of the BTF quickly deviates from the $100 \%$ removal line when reaching loads of about $40 \mathrm{~g} / \mathrm{m}^{3} \mathrm{~h}$.

The CSTB can better withstand shock loads, above all in the case of the twoliquid-phase system which benefits not only from its completely mixed nature 
but also from the buffering effect of the organic phase. When increasing the shock load to higher values, the difference between the one-liquid-phase CSTB and the BTFs becomes somewhat less pronounced.

The inoculated Hyphomicrobium strains became only a minor part of the total bacterial community in both reactors, after long-term operation. Unambiguous detection in the BTF was only possible with the functional gene marker. However, this minor community may play a considerable role in biodegradation despite its relative low abundance.

\section{Acknowledgements}

The present study was financed through a project of the Spanish Ministry of Education and Science (CTM2007-62700/TECNO) and through European FEDER funds. We thank Eldon Rene for his collaboration in some of the last experimental studies.

\section{References}

J.M. Aldric, P. Thonart

Performance evaluation of a water/silicone oil two-phase partitioning bioreactor using Rhodococcus erythropolis T902-1 to remove volatile organic compounds from gaseous effluents

J. Chem. Technol. Biotechnol., 83 (2008), pp. 1401-1408

S.F. Altschul, T.L. Madden, A.A. Schaffer, J.H. Zhang, Z. Zhang, W. Miller, D.J. Lipman

Gapped BLAST and PSI-BLAST: a new generation of protein database search programs

Nucleic Acids Res., 25 (1997), pp. 3389-3402

S. Arriaga, R. Muñoz, S. Hernández, B. Guieysse, S. Revah

Gaseous hexane biodegradation by Fusarium solani in two liquid phase packed bed and stirred-tank bioreactors

Environ. Sci. Technol., 40 (2006), pp. 2390-2395

L. Bailón, Y. Dopico, M. Nikolausz, M. Kästner, M.C. Veiga, C. Kennes

Removal of dichloromethane from waste gases using a fixed-bed biotrickling filter and a continuous stirred tank bioreactor

C. Kennes, M.C. Veiga (Eds.), Proceedings of Biotechniques for Air Pollution Control, University of La Coruña Publisher, La Coruña, Spain (2007), pp. 505-514

N.L. Boudreau, A.J. Daugulis

Transient performance of two-phase partitioning bioreactors treating a toluene contaminated gas stream

Biotechnol. Bioeng., 94 (2006), pp. 448-457 
M.T. Césario, H.H. Beeftink, J. Tramper

Feasibility of using water-immiscible organic solvents in biological waste gas treatment Bioproc. Eng., 12 (1995), pp. 55-63

\section{A.J. Daugulis}

Two-phase partitioning bioreactors: a new technology platform for destroying xenobiotics

Trends Biotechnol., 19 (2001), pp. 457-462

C.T. Davidson, A.J. Daugulis

Addressing biofilter limitations: a two-phase partitioning bioreactor process for the treatment of benzene and toluene contaminated gas streams

Biodegradation, 14 (2003), pp. 415-421

E. Déziel, Y. Comeau, R. Villemur

Two liquid-phase bioreactors for enhanced degradation of hydrophobic/toxic compounds

Biodegradation, 10 (1999), pp. 219-233

DFG (Deutsche Forschungsgemeinschaft)

MAK- und BAT-Werte-Liste 2008, vol. IVWiley-VCH, Weinheim, Germany (2008) $271 \mathrm{pp}$

Diks, R.M.M., 1992. The removal of dichloromethane from waste gases in biological trickling filter. Ph.D. Thesis. Department of Chemical Engineering, Eindhoven University of Technology, The Netherlands.

R.M.M. Diks, S.P.P. Ottengraf

Verification studies of a simplified model for the removal of dichloromethane from waste gases using a biological trickling filter

Bioproc. Eng., 6 (1991), pp. 93-99

R.M.M. Diks, S.P.P. Ottengraf, A.H.C. Van den Oever

The influence of $\mathrm{NaCl}$ on the degradation rate of dichloromethane by Hyphomicrobium sp

Biodegradation, 5 (1994), pp. 129-141

S.J. Ergas, K. Kinney, M.E. Fuller, K.M. Scow

Characterization of a compost biofiltration system degrading dichloromethane

Biotechnol. Bioeng., 44 (1994), pp. 1048-1054

E. Estévez, M.C. Veiga, C. Kennes

Biofiltration of waste gases with the fungi Exophiala oligosperma and Paecilomyces variotii

Appl. Microbiol. Biotechnol., 67 (2005), pp. 563-568

R. Gälli, T. Leisinger

Specialized strains for the removal of dichloromethane from industrial waste

Conserv. Recycling, 8 (1985), pp. 91-100 
S. Hartmans, J. Tramper

Dichloromethane removal from waste gases with a trickle-bed bioreactor

Bioproc. Eng., 6 (1991), pp. 83-92

H. Heuer, M. Krsek, P. Baker, K. Smalla, E.M.H. Wellington

Analysis of actinomycete communities by specific amplification of genes encoding $16 \mathrm{~S}$ rRNA and gel-electrophoretic separation in denaturing gradients

Appl. Environ. Microbiol., 63 (1997), pp. 3233-3241

K. Ishii, M. Fukui

Optimization of annealing temperature to reduce bias caused by a primer mismatch in multitemplate PCR

Appl. Environ. Microbiol., 67 (2001), pp. 3753-3755

Y. Jin, L. Guo, M.C. Veiga, C. Kennes

Fungal biofiltration of $\alpha$-pinene: effects of temperature, relative humidity, and transient loads

Biotechnol. Bioeng., 96 (2007), pp. 433-443

C. Kennes, F. Thalasso

Waste gas biotreatment technology

J. Chem. Technol. Biotechnol., 72 (1998), pp. 303-319

C. Kennes, M.C. Veiga

Conventional biofilters

C. Kennes, M.C. Veiga (Eds.), Bioreactors for Waste Gas Treatment, Kluwer Academic Publishers, Dordrecht, The Netherlands (2001), pp. 47-98 (Chapter 3)

C. Kennes, Y. Jin, M.C. Veiga

Fungal and dechlorinating biocatalysts in waste gas treatment

P.N.L. Lens, C. Kennes, P. LeCloirec, M. Deshusses (Eds.), Waste Gas Treatment for Resource Recovery, IWA Publishing Co., London, UK (2006), pp. 277-301 (Chapter 16)

M. Koutinas, J. Martin, L.G. Peeva, A. Mantalaris, A.G. Livingston

An oil-absorber-bioscrubber system to stabilize biotreatment of pollutants present in waste gas. Fluctuating loads of 1,2-dichloroethane

Environ. Sci. Technol., 40 (2006), pp. 595-602

D.J. Lane

16S/23S rRNA sequencing

E. Stackebrandt, M. Goodfellow (Eds.), Nucleic Acid Techniques in Bacterial Systematics, Wiley, New York (1991), pp. 115-147

A. Massol-Deyá, R. Weller, L. Ríos-Hernández, J.Z. Zhou, R.F. Hickey, J.M. Tiedje Succession and convergence of biofilm communities in fixed-film reactors treating aromatic hydrocarbons in groundwater

Appl. Environ. Microbiol., 63 (1997), pp. 270-276 
J.A. Mendoza, O.J. Prado, M.C. Veiga, C. Kennes

Hydrodynamic behaviour and comparison of technologies for the removal of excess biomass in gas-phase biofilters

Water Res., 38 (2004), pp. 404-413

B.T. Mohammad, M.C. Veiga, C. Kennes

Mesophilic and thermophilic biotreatment of BTEX-polluted air in reactors

Biotechnol. Bioeng., 97 (2007), pp. 1423-1438

S. Moller, A.R. Pedersen, L.K. Poulsen, E. Arvin, S. Molin

Activity and three-dimensional distribution of toluene-degrading Pseudomonas putida in a multispecies biofilm assessed by quantitative in situ hybridization and scanning confocal laser microscopy

Appl. Environ. Microbiol., 62 (1996), pp. 4632-4640

S.C. Moura, R. Ferreira Jorge, A. Duque, R.A.R. Boaventura, P.N.L. Castro

Aerobic biological treatment of waste waters containing dichloromethane

J. Chem. Technol. Biotechnol., 82 (2007), pp. 864-869

D.R. Nielsen, A.J. Daugulis, P.J. McLellan

Transient performance of a two-phase partitioning bioscrubber treating a benzenecontaminated gas stream

Environ. Sci. Technol., 39 (2005), pp. 8971-8977

M. Nikolausz, U. Kappelmeyer, I. Nijenhuis, M. Kästner

Molecular characterization of dichloromethane-degrading Hyphomicrobium strains using 16S rDNA and DCM dehalogenase gene sequence

Syst. Appl. Microbiol., 28 (2005), pp. 582-587

M. Nikolausz, I. Nijenhuis, K. Ziller, H. Richnow, M. Kästner

Stable carbon isotope fractionation during degradation of dichloromethane by methylotrophic bacteria

Environ. Microbiol., 8 (2006), pp. 156-164

W.J.H. Okkerse, S.P.P. Ottengraf, B. Osinga-Kuipers, M. Okkerse

Biomass accumulation and clogging in biotrickling filters for waste gas treatment. Evaluation of a dynamic model using dichloromethane as a model pollutant

Biotechnol. Bioeng., 63 (1999), pp. 418-430

T.A.C. Oliveira, A.G. Livingston

Bioscrubbing of waste gas - substrate absorber to avoid instability induced by inhibition kinetics

Biotechnol. Bioeng., 84 (2003), pp. 552-563

B. Sercu, D. Núñez, H. Van Langenhove, G. Aroca, W. Verstraete

Operational and microbiological aspects of a bioaugmented two-stage biotrickling filter removing hydrogen sulfide and dimethyl sulfide

Biotechnol. Bioeng., 90 (2005), pp. 259-269 
R. Sipos, A.J. Székely, M. Palatinszky, S. Révész, K. Márialigeti, M. Nikolausz Effect of primer mismatch, annealing temperature and PCR cycle numbers on $16 \mathrm{~S}$ rRNA gene targeting bacterial community analysis

FEMS Microbiol. Ecol., 60 (2007), pp. 341-350

J.W. Van Groenestijn, M.E. Lake

Elimination of alkanes from off-gases using biotrickling filters containing two liquid phases

Environ. Prog., 18 (1999), pp. 151-155

S. Vuilleumier, N. Ivos, M. Dean, T. Leisinger

Sequence variation in dichloromethane dehalogenases/glutathione $S$-transferases

Microbiology-SGM, 147 (2001), pp. 611-619 